\title{
Results of immunohistochemistry in the differential diagnosis of early hepatocellular carcinoma and nodules with high-grade dysplasia in patients with cirrhosis
}

\author{
Gabriela Perdomo CORAL'1, Fernanda BRANCO ${ }^{2}$, Rosalva MEURER ${ }^{3}$, \\ Patrícia dos Santos MARCON ${ }^{1,4}$, Paulo Roberto 0tt FONTES ${ }^{1}$ and Angelo Alves de MATTOS ${ }^{1}$
}

\begin{abstract}
Background - Hepatocellular carcinoma (HCC) is the most frequent primary cancer of the liver and cirrhosis is considered a pre-malignant disease. In this context, the evolutionary sequence from low grade dysplastic nodule and high grade dysplastic nodule (HGDN) to early HCC and advanced HCC has been studied. The differential diagnosis between HGDN and early HCC is still a challenge, especially in needle biopsies Objective - To evaluate an immunohistochemistry panel to differentiate dysplastic nodules and HCC. Methods - Patients with cirrhosis who underwent surgical resection or liver transplantation were included. The sensitivity, specificity and accuracy for the diagnosis of neoplasia were analyzed by evaluating five markers: heat shock protein 70 , glypican 3 , glutamine synthetase, clathrin heavy chain and beta-catenin. $P \leq 0.05$ was considered statistically significant. Results - One hundred and fifty-six nodules were included; of these, 57 were HCC, 14 HGDN, 18 low grade dysplastic nodules and 67 regenerative macronodules. Sensitivity of HCC diagnosis was $64.9 \%$ for glypican 3 and $77.2 \%$ for glutamine syntetase, while specificity was $96.0 \%$ and $96.0 \%$ respectively. When the panel of four markers was considered (excluding beta catenin), the specificity ranged from $87.9 \%$ for one positive marker to $100 \%$ for at least three markers. The best accuracy for HCC diagnosis was obtained with at least two positive markers, which was associated with a sensitivity of $82.5 \%$ and specificity of $99 \%$. Conclusion - Differential diagnosis of dysplastic nodules and HCC by morphological criteria can be challenging. Immunomarkers are useful and should be used for the differential diagnosis between HCC and HGDN.
\end{abstract}

HEADINGS - Hepatocellular carcinoma. Glutamate synthase. Glypicans.

\section{INTRODUCTION}

Hepatocellular carcinoma (HCC) is the most frequent primary liver cancer and the second major cause of death among malignant neoplasms. Moreover, there is a projection of increased prevalence of this neoplasia in the next 10 years worldwide ${ }^{(1-4)}$. Liver cirrhosis is considered a pre-malignant disease, with a risk of developing $\mathrm{HCC}^{(3)}$. In this regard, the following evolutionary sequences have been demonstrated: low grade dysplastic nodule (LGDN), high grade dysplastic nodule (HGDN), early HCC and advanced $\mathrm{HCC}^{(5-}$ 9. The differential diagnosis between HGDN and early HCC has been the subject of several studies. Histological differentiation by morphological analysis alone is not possible most of the time, especially in needle biopsies ${ }^{(7,10,11)}$.

Di Tommaso et al. ${ }^{(12)}$, demonstrated the validity of heat shock protein 70 (HSP70), glypican 3 (GPC3) and glutamine synthetase (GS) as immunohistochemical markers in this setting. Using the three markers' panel the positivity for at least two of the three markers, regardless of which one resulted in a sensitivity of $72 \%$ and a specificity of $100 \%$ for the diagnosis of early HCC. When a fourth immunohistochemical marker, clathrin heavy chain (CHC), was added to the panel, there was an increase in sensitivity and diagnostic accuracy of this neoplasm ${ }^{(13)}$. A prospective study carried out subsequently validated the role of the immunomarker panel, however, the panel only slightly increases the diagnostic accuracy in an expert setting ${ }^{(14)}$. More recently, Uthamalingam et al. evaluating a population in a non-western country, failed to confirm these results, mainly in patients without cirrhosis, and showed low sensitivity for routine diagnosis of $\mathrm{HCC}^{(15)}$.

Another promising immunohistochemical marker in the identification of HCC is the anti-beta catenin antibody. The mutation in beta catenin exon three has been detected in this neoplasm and in the adenoma with a risk of malignant transformation $^{(16,17)}$. Furthermore, current data suggest that mutations

Declared conflict of interest of all authors: none

Disclosure of funding: Bayer Pharmaceuticals.

1 Universidade Federal de Ciências da Saúde de Porto Alegre (UFCSPA), Programa de Pós-Graduação em Medicina: Hepatologia, Porto Alegre, RS, Brasil. ${ }^{2}$ Irmandade da Santa Casa de Misericórdia de Porto Alegre, Departamento de Radiologia, Porto Alegre, RS, Brasil. ${ }^{3}$ UFCSPA, Departamento de Patologia, Porto Alegre, RS, Brasil. ${ }^{4}$ Hospital Mãe de Deus, Departamento de Gastroenterologia, Porto Alegre, RS, Brasil.

Corresponding author: Patrícia dos Santos Marcon, MD, MSc. E-mail: patekape|@hotmail.com 
predicted to activate the beta catenin pathway were associated with maintenance of tumor initiating cells, tumor progression, metastasis and drug resistance, especially innate resistance to immune checkpoint blockade ${ }^{(18,19)}$.

Therefore, the aim of the present study was to evaluate the sensitivity, specificity and accuracy of the GS, GPC3, HSP70 and $\mathrm{CHC}$ markers and to study the influence of beta catenin, added to the panel of four markers, in the diagnosis of HCC.

\section{METHODS}

Consecutive patients with hepatic cirrhosis who underwent surgical resection or liver transplantation were studied at the Hospital Irmandade Santa Casa de Misericórdia de Porto Alegre (ISCMPA), a tertiary hospital in Southern Brazil. The diagnosis of $\mathrm{HCC}$, prior to the procedure, was performed through imaging according to established criteria or by a liver biopsy ${ }^{(20)}$.

Surgical specimens and explanted livers were fixed in a $10 \%$ formalin solution and subjected first to macroscopic analysis. Macro-nodule was defined when the size or texture of the nodule differs from the background cirrhotic nodules, when reaching 5 $\mathrm{mm}$ or more ${ }^{(21)}$. Subsequently, the macro-nodules were designated, embedded in paraffin, sectioned and stained with hematoxylin and eosin and classified into regenerative macro-nodules (RMN), LGDN, HGDN, early HCC and advanced HCC ${ }^{(22)}$. HCCs were identified according to the Japanese classifications of histologically as well, moderately or poorly differentiated ${ }^{(23)}$. The gold standard to define HCC, was histopathology, mainly presence of stromal invasion and the loss of reticulin framework. Other findings are the grade of nuclear atypia, high nuclear to cytoplasmic ratio and architectural atypia ${ }^{(9)}$. Patients with $\mathrm{HCC}$ beyond Milan criteria that were awaiting liver transplantation undergoing transarterial chemoembolization (TACE) as a bridge to transplant. Nodules with $100 \%$ necrosis were excluded.

To perform the immunohistochemistry, the blocks were sectioned in thicknesses of three microns, dewaxed and rehydrated. The Reveal HPR System, SPRING ${ }^{\circledR}$ Kit was used to detect proteins: anti-beta catenin (E247) at a dilution of 1/200 (ABCAM $\left.{ }^{\circledR}\right)$, antiGS at a dilution of $1 / 400\left(\mathrm{ABCAM}^{\circledR}\right)$, anti-HSP70 at a dilution of $1 / 300\left(\mathrm{ABCAM}^{\circledR}\right)$, anti-CHC at a $1 / 1000$ dilution $\left(\mathrm{ABCAM}^{\circledR}\right)$ and anti-GPC3 $(1 \mathrm{G} 12)$ at a $1 / 400$ dilution $\left(\mathrm{ABCAM}^{\circledR}\right)$. Antigenic recovery was performed with sodium citrate $(\mathrm{pH} 6.0)$ for 40 minutes. Endogenous peroxidase activity was blocked using two baths of 10 -minute hydrogen peroxide $\left(\mathrm{H}_{2} \mathrm{O}_{2}\right) 30$ volumes, at $5 \%$ volumes in methanol. Blocking of nonspecific activities was performed with a $1 \%$ bovine albumin serum for one hour. Incubation with the primary antibodies was performed overnight at $4^{\circ} \mathrm{C}$. Incubation with secondary antibodies was performed for 30 minutes at room temperature. For negative control of the technique, the same tissues were used incubated with the same antibodies, except the primary one which was replaced by a $1 \%$ BSA (bovine serum albumin). The antigen-antibody binding was visualized with the chromogen DAB (diaminobenzidine). Counter staining was done with Harris hematoxylin; The slides were dehydrated and mounted with a synthetic resin. Cases were considered positive when at least $5 \%$ of cells showed staining and were classified according to the intensity (weak, moderate or accentuated) and its classification as focal or diffuse.

For statistical analysis SPSS software (StatisticalPackage for Social Sciences) version 17.0 was used. Quantitative variables were described using mean and standard deviation (symmetric distribution) or median (asymmetric distribution). The sensitivity, specificity and accuracy for the diagnosis of HCC were analyzed by first evaluating the five markers (GS, GPC3, HSP70, CHC and beta-catenin) and then the four markers (excluding beta catenin). The value of $P \leq 0.05$ was considered statistically significant.

Informed consent was obtained from each patient included in the study and the study protocol is in accordance of ethical guidelines from the National Health Council of the Ministry of Health (Brazil- Resolution 466/2012) and the 1975 Declaration of Helsinki. The study was approved by the ISCMPA Research Committee.

\section{RESULTS}

Fifty-one patients were included. Seventeen of these underwent liver resection and 34 were submitted to orthotopic liver transplantation. Thirty-six patients $(70.6 \%)$ were male. The mean age of the patients was 59.7 and the median was 64.0 (ranging from 42 to 75 years).

One hundred and fifty-six nodules were evaluated after the exclusion of two nodules due to complete necrosis. Patients submitted to surgical resection had a single nodule, all classified as HCC, with a diameter varying from $1.0 \mathrm{~cm}$ to $3.2 \mathrm{~cm}$ with a median of $1.9 \mathrm{~cm}$. Patients submitted to liver transplantation had a mean number of nodules per patient of 3.18 and median 2.0 (ranging from 1 to 6 nodules) with a diameter varying from $0.7 \mathrm{~cm}$ to 4.0 $\mathrm{cm}$ with a median of $2.0 \mathrm{~cm}$. Of these, 40 were $\mathrm{HCC}, 14 \mathrm{HDGN}$, 18 LGDN and 67 RMN.

Regarding HCC, histological classification identified 22 nodules with well differentiated HCC and 35 with moderately differentiated / poorly differentiated $\mathrm{HCC}$.

Individual sensitivity in cases of HCC diagnosis was $18.5 \%$ for beta catenin, 45.6\% for HSP70, 61.4\% for CHC, 64.9\% for GPC3 and $77.2 \%$ for GS. Positive cases of HCC with the most important markers are shown in FIGURE 1.

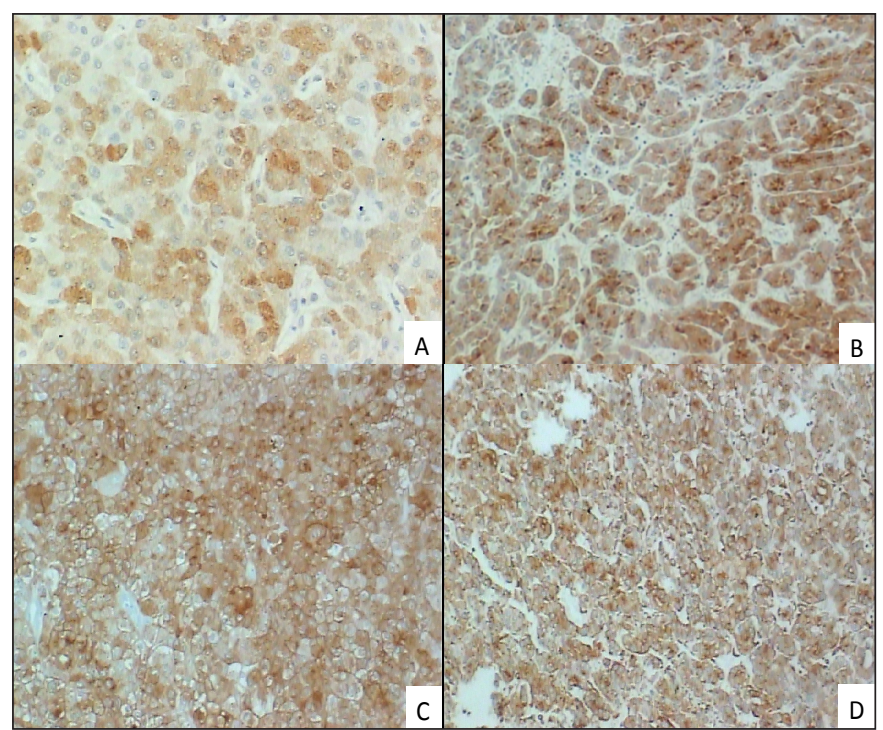

FIGURE 1. Hepatocellular carcinoma. Positive markers: (A) glutamine synthetase [GS]; (B) glipican 3 [GPC3]; (C) heat shock protein 70 [HSP70]; (D) clathrin heavy chain [CHC]. 
When the panel of four markers was considered (excluding beta catenin in view of its low sensitivity when performed in isolation; in fact, just in one case, beta catenin was the only positive marker, but the diagnosis was HGDN), the sensitivity ranged from $10.5 \%$ for positivity of all markers to $96.5 \%$ for the positivity of only one marker. Specificity ranged from $87.9 \%$ for one marker to $100 \%$ for at least three markers. The diagnostic accuracy ranged from $67.3 \%$ when all four markers were considered to $92.9 \%$ when considering at least two positive markers. The best accuracy was obtained when considering at least two positive markers, which was associated with a sensitivity of $82.5 \%$ and specificity of $99 \%$ (TABLE 1 ).

TABLE 1. Sensitivity, specificity and accuracy for the diagnosis of HCC with four markers.

\begin{tabular}{|c|c|c|c|c|c|}
\hline \multirow{2}{*}{$\begin{array}{l}\text { Positive } \\
\text { markers }\end{array}$} & \multirow{2}{*}{$\begin{array}{c}\text { Non } \\
\text { HCC } \\
(n=99)\end{array}$} & \multirow{2}{*}{$\begin{array}{c}\text { HCC } \\
(n=57)\end{array}$} & \multicolumn{3}{|c|}{ HCC } \\
\hline & & & $\begin{array}{c}\text { Sensitivity } \\
(\%)\end{array}$ & $\begin{array}{c}\text { Specificity } \\
(\%)\end{array}$ & $\begin{array}{c}\text { Accuracy } \\
(\%)\end{array}$ \\
\hline
\end{tabular}

4M Panel

$\begin{array}{lccccc}\text { All four } & 0 & 6 & 10.5 & 100 & 67.3 \\ \text { At least } 3 & 0 & 26 & 45.6 & 100 & 80.1 \\ \text { At least } 2 & 1 & 47 & 82.5 & 99.0 & 92.9 \\ \text { At least } 1 & 12 & 55 & 96.5 & 87.9 & 91.0 \\ \text { GS } & 4 & 44 & 77.2 & 96.0 & 89.1 \\ \text { GPC3 } & 4 & 37 & 64.9 & 96.0 & 84.6 \\ \text { HSP70 } & 3 & 26 & 45.6 & 97.0 & 78.2 \\ \text { CHC } & 2 & 27 & 61.4 & 97.9 & 86.3\end{array}$

HCC: hepatocellular carcinoma; GS: Glutamine Synthetase; GPC3: glypican 3; HSP70: Heat Shock Protein 70; CHC: Clathrin heavy chain; $4 \mathrm{M}$ Panel: panel with 4 immunomarkers.

\section{DISCUSSION}

The development of HCC is more frequent in patients with HDGN as compared to $\mathrm{LGDN}^{(24)}$. A clinical follow-up study demonstrated that HGDN shows a malignant transformation risk of approximately $30 \%$ to $40 \%$ in 24 months $^{(25)}$. Evidence of malignant transformation of HGDN is the fact that some of these nodules exhibit a well differentiated HCC microscopic focus ${ }^{(26)}$. In the study by Borzio et al., 31\% of HGDNs exhibit malignant transformation at a mean follow-up of 33 months $^{(27)}$. Similarly, the study by Kobayashi et al. demonstrated that the relative risk of developing HCC from HGDN was $46.2 \%, 61.5 \%$ and $80.8 \%$ at 1,3 and 5 years respectively ${ }^{(28)}$. More recently, these findings have been confirmed, with dysplastic nodules being considered high-risk pre-malignant lesions ${ }^{(29)}$.

Regarding $\mathrm{HCC}$ in a patient with hepatic cirrhosis, it is recommended that the patient be submitted to screening and surveillance every 6 months. When nodules larger than $1 \mathrm{~cm}$ are found, dynamic imaging study for diagnosis should be performed. If necessary for a better diagnostic clarification a liver biopsy is recommended ${ }^{(20,30)}$.

Some studies have shown that the non-invasive diagnosis of HCC may present false positive results ${ }^{(31-33)}$. Hayashi et al. ${ }^{(31)}$ demonstrated that in 8 of $30(27 \%)$ patients transplanted by HCC, neoplasia was not confirmed in the explant, which resulted in an incorrect organ allocation in these patients. Wiesner et al. ${ }^{(32)}$ showed that $31 \%$ of patients who underwent liver transplantation for nodules smaller than or equal to $1.9 \mathrm{~cm}$ and $9 \%$ of patients with nodules between 2 and $5 \mathrm{~cm}$ had no evidence of neoplasia in the explanted liver. Similar results were also found in a French study, where the false-positive diagnosis of HCC in pre-transplants occurred in $20 \%$ of the patients ${ }^{(33)}$. On the other hand, a false-positive rate $<3 \%$ was detected in a cohort of Asian patients after liver resection ${ }^{(34)}$.

We want to emphasize here that the danger of invasive treatments in lesions misdiagnosed is greater than the minimal risks of liver biopsy ${ }^{(35)}$. Therefore, especially in non-typical cases, a biopsy is critical for diagnostic elucidation.

Furthermore, biopsy can also assess prognostic parameters like tumor differentiation and is crucial for differential diagnosis with intra-hepatic cholangiocarcinoma. On the other hand, from the morphological point of view, the differentiation of HGDN and early $\mathrm{HCC}$ by needle biopsy presents a diagnostic challenge and is sometimes impossible to establish. Both HGDN and HCC may present cell population enlargement, cytoplasmic basophilia, hyperchromasia and nuclear atypia, altered nucleus cytoplasm ratio, reduced number of portal spaces, macrotrabecula and pseudoacinar transformation ${ }^{(9,22)}$. The only characteristic that differentiates HCC from HGDN is stromal invasion, which is difficult to detect in needle biopsy ${ }^{(36)}$.

The recent identification of immunomarkers in this differentiation has been extremely useful for a more accurate diagnosis ${ }^{(37,38)}$. GPC3 has been the most studied marker; literature shows a sensitivity between $75.7 \%$ and $94.8 \%$ and specificity of $96 \%$ to $97 \% \%^{(39-44)}$. On the other hand, the negativity for GPC3 does not exclude the diagnosis of HCC, especially in cases of needle biopsy, since immuno staining can be heterogeneous. With respect to dysplastic lesions, Wang et al. ${ }^{(39)}$ demonstrated that $10.6 \%$ of these nodules exhibited GPC3. In the study by Coston et al. ${ }^{(41)}$, the GPC3 was present in $7 \%$ of LGDN and in $23 \%$ of HGDN. In the present study, the sensitivity of GPC3 for the diagnosis of HCC was approximately $65 \%$ and the specificity was $96 \%$.

Di Tommaso et al. ${ }^{(13)}$ showed that $\mathrm{CHC}$ was the most sensitive isolated marker for the diagnosis of well differentiated HCC, demonstrating sensitivity of $58.8 \%$, versus GS $(41.2 \%)$, HSP70 $(17.6 \%)$ and GPC3 (11.8\%). In the present study, the isolated marker with the highest sensitivity and specificity was GS with $77.2 \%$ sensitivity, $96 \%$ specificity and $89.1 \%$ accuracy. The specificity for each marker alone was above $95 \%$, with the exception of the beta-catenin marker, which also had a very low sensitivity. The mutation of beta catenin may be present in HCC, but some authors have demonstrated its presence in the minority of patients, which confirms our findings ${ }^{(17,45)}$. On the other hand, some researches have shown the presence of changes in the beta-catenin pathway in about $50 \%$ of the analyzed tumors, with prognostic and therapeutic importance ${ }^{(46-49)}$. Thus, the use of beta-catenin in the histological diagnosis of HCC does not play a prominent role, which differs from the perspectives of HCC treatment.

In the study by Di Tommaso et al. ${ }^{(12)}$, performed on surgical biopsies, analyzing 52 non-malignant nodules and $53 \mathrm{HCC}$, the negativity for all the markers (HSP70, GPC3 and GS) was found in $100 \%$ of the cases of regenerative nodules. In contrast, positiv- 
ity for all markers was present in less than half of the early HCCs. The positivity for 2 out of 3 markers had a sensitivity of $70 \%$ and a specificity of $100 \%$. Similarly, a study using this panel of needle biopsies demonstrated an accuracy for the diagnosis of HCC of $78.4 \%$ (2 positive markers) with $100 \%$ specificity ${ }^{(50)}$. Including the $\mathrm{CHC}$, the panel of 4 markers demonstrated that positivity for at least 2 markers obtained an accuracy of $97 \%$ for $\mathrm{HCC}^{(13)}$. In the present study, analyzing 99 non-malignant nodules and $57 \mathrm{HCC}$, the best diagnostic accuracy for $\mathrm{HCC}$ was also related to the positivity of at least two markers $(92.9 \%)$ with a specificity of $99 \%$.

It is noteworthy that Sherman ${ }^{(51)}$, in an editorial, questions the real importance of these immunomarkers in the differential diagnosis of HCC and HGDN, especially because the diagnosis of neoplasm is performed according to morphological criteria. In fact, the most important apply of the immunomarkers are nodules less than $2 \mathrm{~cm}$, but can be of value in greater nodules, mainly if they are well-differentiated.

The possible limitations of this study were the retrospective designed and inclusion of moderate and poor differentiated neoplasia in the differential diagnosis of hepatic nodules.

\section{CONCLUSION}

The fact that most pathologists do not have expertise in the differential diagnosis of dysplastic nodules and HCC by morphological criteria, makes the immunohistochemical markers of great value. Thus, we conclude that the HSP70, GPC3, GS and CHC markers are useful and should be used mainly for the differential diagnosis between HCC and HGDN.

\section{ACKNOWLEDGMENTS}

The authors thanks Bayer Pharmaceuticals for financial support and Ceres Andreia Vieira de Oliveira for statistical analysis.

\section{Authors' contribution}

Coral GP: contributed for analysis and interpretation of data, statistical analysis, drafting of the manuscript, critical revision of the manuscript for important intellectual content and approval of the final version of the manuscript. Branco F: contributed for the study concept and design, analysis and interpretation of data and approval of the final version of the manuscript. Meurer R: contributed for acquisition of data, analysis and interpretation of data and approval of the final version of the manuscript. Marcon PS: drafting of the manuscript, critical revision of the manuscript and approval of the final version of the manuscript. Fontes PRO: contributed for the study concept and design and approval of the final version of the manuscript. Mattos AA: contributed for the study concept and design, analysis and interpretation of data, critical revision of the manuscript for important intellectual content and approval of the final version of the manuscript.

\section{Orcid}

Gabriela Perdomo Coral: 0000-0003-4318-2871.

Fernanda Branco: 0000-0002-8066-3677.

Rosalva Meurer: 0000-0001-8394-299X.

Patrícia dos Santos Marcon: 0000-0001-8086-4826.

Paulo Roberto Ott Fontes: 0000-0002-0217-3496.

Angelo Alves de Mattos: 0000-0003-2417-9765.

Coral GP, Branco F, Meurer R, Marcon PS, Fontes PRO, Mattos AA. Papel da imunohistoquímica no diagnóstico diferencial do carcinoma hepatocelular precoce e dos nódulos com displasia de alto grau em pacientes com cirrose. Arq Gastroenterol. 2021;58(1):82-6.

RESUMO - Contexto - O carcinoma hepatocelular (CHC) é o câncer primário do fígado mais frequente e a cirrose é considerada uma doença pré-maligna. Nesse contexto, a sequência evolutiva do nódulo displásico de baixo grau e nódulo displásico de alto grau (NDAG) para CHC precoce e CHC avançado tem sido estudada. O diagnóstico diferencial entre NDAG e CHC precoce ainda é um desafio, principalmente em biópsias por agulha. Objetivo - Avaliar um painel de imunohistoquímica para diferenciar nódulos displásicos de CHC. Métodos - Foram incluídos pacientes com cirrose submetidos à ressecção cirúrgica ou transplante de fígado. A sensibilidade, especificidade e acurácia para o diagnóstico da neoplasia foram analisadas avaliando cinco marcadores: proteína de choque térmico $70 \mathrm{kDa}$, glipican 3 , glutamina sintetase, clatrina de cadeia pesada e beta-catenina. $P \leq 0,05$ foi considerado estatisticamente significativo. Resultados - Cento e cinquenta e seis nódulos foram incluídos; destes, 57 eram CHC, 14 NDAG, 18 nódulos displásicos de baixo grau e 67 macronódulos regenerativos. A sensibilidade do diagnóstico de CHC foi de 64,9\% para glipican 3 e 77,2\% para glutamina sintetase, enquanto a especificidade foi de $96,0 \%$ e $96,0 \%$, respectivamente. Quando o painel de quatro marcadores foi considerado (excluindo beta catenina), a especificidade variou de $87,9 \%$ para um marcador positivo a $100 \%$ para pelo menos três marcadores. A melhor acurácia para o diagnóstico de CHC foi obtida com pelo menos dois marcadores positivos, o que foi associado a uma sensibilidade de $82,5 \%$ e especificidade de $99 \%$. Conclusão - O diagnóstico diferencial de nódulos displásicos e CHC por critérios morfológicos pode ser desafiador. Imunomarcadores são úteis e devem ser usados para o diagnóstico diferencial entre CHC e NDAG.

DESCRITORES - Carcinoma hepatocelular. Glutamato sintase. Glipicanas.

\section{REFERENCES}

1. McGlynn KA, Petrick JL, El-Serag HB. Epidemiology of hepatocellular carcinoma. Hepatology. 2020. doi: 10.1002/hep.31288.

2. Sayiner M, Golabi P, Younossi ZM. Disease Burden of Hepatocellular Carcinoma: A Global Perspective. Dig Dis Sci. 2019;64:910-7.

3. Yang JD, Hainaut P, Gores GJ, Amadou A, Plymoth A, Roberts LR. A global view of hepatocellular carcinoma: trends, risk, prevention and management. Nat Rev Gastroenterol Hepatol. 2019;16:589-604.

4. Valery PC, Laversanne M, Clark PJ, Petrick JL, McGlynn KA, Bray F. Projections of primary liver cancer to 2030 in 30 countries worldwide. Hepatology. 2018;67:600-11.
5. Park YN. Update on precursor and early lesions of hepatocellular carcinomas. Arch Pathol Lab Med. 2011;135:704-15.

6. Craig AJ, von Felden J, Garcia-Lezana T, Sarcognato S, Villanueva A. Tumour evolution in hepatocellular carcinoma. Nat Rev Gastroenterol Hepatol. 2020;17:139-52.

7. Roskams T, Kojiro M. Pathology of early hepatocellular carcinoma: conventional and molecular diagnosis. Semin Liver Dis. 2010;30:17-25.

8. Roncalli M, Borzio M, Di Tommaso L. Hepatocellular dysplastic nodules. Hepatol Res. 2007;37 (Suppl 2):S125-34.

9. Wanless IR. International consensus on histologic diagnosis of early hepatocellular neoplasia. Hepatol Res. 2007;37 (Suppl 2):S139-41. 
10. Roncalli M, Terraccianob L, Di Tommaso L, David E, Colombo M; Gruppo Italiano Patologi Apparato Digerente (GIPAD); Società Italiana di Anatomia Patologica e Citopatologia Diagnostica/International Academy of Pathology, Italian division (SIAPEC/IAP). Dig Liver Dis. 2011;43 (Suppl 4):S361-72.

11. Quaglia A. Hepatocellular carcinoma: a review of diagnostic challenges for the pathologist. J Hepatocell Carcinoma. 2018;5:99-108.

12. Di Tommaso L, Franchi G, Park YN, Fiamengo B, Destro A, Morenghi E, et al Diagnostic value of HSP70, glypican 3, and glutamine synthetase in hepatocellular nodules in cirrhosis. Hepatology. 2007;45:725-34.

13. Di Tommaso L, Destro A, Fabbris V, Spagnuolo G, Laura Fracanzani A, Fargion $\mathrm{S}$, et al. Diagnostic accuracy of clathrin heavy chain staining in a marker panel for the diagnosis of small hepatocellular carcinoma. Hepatology. 2011;53 1549-57.

14. Tremosini S, Forner A, Boix L, Vilana R, Bianchi L, Reig M, et al. Prospective validation of an immunohistochemical panel (glypican 3, heat shock protein 70 and glutamine synthetase) in liver biopsies for diagnosis of very early hepatocellular carcinoma. Gut. 2012;61:1481-7.

15. Uthamalingam P, Das A, Behra A, Kalra N, Chawla Y. Diagnostic Value of Glypican3, Heat Shock Protein 70 and Glutamine Synthetase in Hepatocellula Carcinoma Arising in Cirrhotic and Non-Cirrhotic Livers. J Clin Exp Hepatol. 2018;8:173-80.

16. Hsu HC, Jeng YM, Mao TL, Chu JS, Lai PL, Peng SY. Beta-catenin mutations are associated with a subset of low-stage hepatocellular carcinoma negative for hepatitis B virus and with favorable prognosis. Am J Pathol. 2000;157:763-70.

17. Suarez IM, Uribe D, Jaramillo CM, Osorio G, Perez JC, Lopez R, et al. Wnt/beta catenin signaling pathway in hepatocellular carcinomas cases from Colombia. Ann Hepatol. 2015;14:64-74

18. Harding JJ, Nandakumar S, Armenia J, Khalil DN, Albano M, Ly M, et al Prospective Genotyping of Hepatocellular Carcinoma: Clinical Implications of Next-Generation Sequencing for Matching Patients to Targeted and Immune Therapies. Clin Cancer Res. 2019;25:2116-26.

19. Wang W, Smits R, Hao H, He C. Wnt//-Catenin Signaling in Liver Cancers. Cancers (Basel). 2019;11:926.

20. European Association for the Study of the Liver. EASL Clinical Practice Guidelines: Management of hepatocellular carcinoma. J Hepatol. 2018;69:182-236.

21. Wanless IR. Liver biopsy in the diagnosis of hepatocellular carcinoma. Clin Liver Dis. 2005;9:281-5.

22. International Working Party. Terminology of nodular hepatocellular lesions. Hepatology. 1995;22:983-93

23. Kojiro M. Pathology of early HCC-progression from early to advanced. Hepatogastroenterology. 1998;45:1203-5.

24. Iavarone M, Manini MA, Sangiovanni A, Fraquelli M, Forzenigo LV, Di Tommaso L, et al. Contrast-enhanced computed tomography and ultrasound-guided liver biopsy to diagnose dysplastic liver nodules in cirrhosis. Dig Liver Dis. 2013;45:43-9.

25. Di Tommaso L, Sangiovanni A, Borzio M, Park YN, Farinati F, Roncalli M, et al. Advanced precancerous lesions in the liver. Best Pract Res Clin Gastroenterol 2013;27:269-84

26. Kojiro M. Focus on dysplastic nodules and early hepatocellular carcinoma: an eastern point of view. Liver Transpl. 2001;10 (2 Suppl 1):S3-8

27. Borzio M, Fargion S, Borzio F, Fracanzani AL, Croce AM, Stroffolini T, et al. Impact of large regenerative, low grade and high grade dysplastic nodules in hepatocellular carcinoma development. J Hepatol. 2003;39:208-14.

28. Kobayashi M, Ikeda K, Hosaka T, Sezaki H, Someya T, Akuta N, et al. Dysplastic nodules frequently develop into hepatocellular carcinoma in patients with chronic viral hepatitis and cirrhosis. Cancer. 2006;16:636-47.

29. Sato T, Kondo F, Ebara M, Sugiura N, Okabe S, Sunaga M, et al. Natural history of large regenerative nodules and dysplastic nodules in liver cirrhosis: 28-year follow-up study. Hepatol Int. 2015;9:330-6.

30. Heimbach JK, Kulik LM, Finn RS, Sirlin CB, Abecassis MM, Roberts LR, et al AASLD Guidelines for the Treatment of Hepatocellular Carcinoma. Hepatology. 2018;67:358-80
31. Hayashi PH, Trotter JF, Forman L, Kugelmas M, Steinberg T, Russ P, et al Impact of pretransplant diagnosis of hepatocellular carcinoma on cadveric liver allocation in the era of MELD. Liver Transpl. 2004;10:42-8.

32. Wiesner RH, Freeman RB, Mulligan DC. Liver transplantation for hepatocellular cancer: the impact of the MELD allocation policy. Gastroenterology. 2004;127 (5 Suppl 1): S261-7.

33. Compagnon P, Grandadam S, Lorho R, Turlin B, Camus C, Jianrong Y, et al Liver transplantation for hepatocellular carcinoma without a preoperative tumor biopsy. Transplantation. 2008;86:1068-76

34. Lee H, Yoon JH, Kim H, Yi NJ, Hong SK, Yoon KC, et al. False Positive Diagnosis of Hepatocellular Carcinoma in Liver Resection Patients. J Korean Med Sci. 2017;32:315-20.

35. Boyum JH, Atwell TD, Schmit GD, Poterucha JJ, Schleck CD, Harmsen WS, et al. Incidence and Risk Factors for Adverse Events Related to Image-Guided Liver Biopsy. Mayo Clin Proc. 2016;91:329-35.

36. International Consensus Group for hepatocellular Neoplasia. Pathologic diagnosis of early hepatocellular carcinoma: a report of the international consensus group for hepatocellular neoplasia. Hepatology. 2009;49:658-64.

37. Lo RC, Ng IO. Hepatocellular tumors: immunohistochemical analyses for classification and prognostication. Chin J Cancer Res. 2011;23:245-53.

38. Nguyen T, Phillips D, Jain D, Torbenson M, Wu TT, Yeh MM, et al. Comparison of 5 Immunohistochemical Markers of Hepatocellular Differentiation for the Diagnosis of Hepatocellular Carcinoma. Arch Pathol Lab Med. 2015;139:1028-34

39. Wang HL, Anatelli F, Zhai QH, Adley B, Chuang ST, Yang XJ. Glypican-3 as a useful diagnostic marker that distinguishes hepatocellular carcinoma from benign hepatocellular mass lesions. Arch Pathol Lab Med. 2008;132:1723-8.

40. Capurro M, Wanless IR, Sherman M, Deboer G, Shi W, Miyoshi E, et al. Glypican-3: a novel serum and histochemical marker for hepatocellular carcinoma. Gastroenterology. 2003;125:89-97.

41. Coston WMP, Loera S, Lau SK, Ishizawa S, Jiang Z, Wu CL, et al. Distinction of hepatocellular carcinoma from benign hepatic mimickers using glypican-3 and CD34 immunohistochemistry. Am J Surg Pathol. 2008;32:433-44.

42. Libbrecht L, Severi T, Cassiman D, Vander Borght S, Pirenne J, Nevens F, et al. Glypican-3 expression distinguishes small hepatocellular carcinomas from cirrhosis, dysplastic nodules, and focal nodular hyperplasia-like nodules. Am J Surg Pathol. 2006;30:1405-11.

43. Liu H, Li P, Zhai Y, Qu CF, Zhang LJ, Tan YF, et al. Diagnostic value of glypican-3 in serum and liver for primary hepatocellular carcinoma. World $\mathrm{J}$ Gastroenterol. 2010;16:4410-5.

44. Shirakawa $\mathrm{H}$, Kuronuma T, Nishimura $\mathrm{Y}$, Hasebe T, Nakano M, Gotohda N, et al. Glypican-3 is a useful diagnostic marker for a component of hepatocellular carcinoma in human liver cancer. Int J Oncol. 2009;34:649-56.

45. Okabe H, Kinoshita H, Imai K, Nakagawa S, Higashi T, Arima K, et al. Diverse basis of $\beta$-catenin activation in human hepatocellular carcinoma: implications in biology and prognosis. PloS One. 2016;11:e0152695.

46. Khalaf AM, Fuentes D, Morshid AI, Burke MR, Kaseb AO, Hassan M, et al. Role of Wnt/ $\beta$-catenin signaling in hepatocellular carcinoma, pathogenesis, and clinical significance. J Hepatocell Carcinoma. 2018;5:61-73.

47. Choi WT, Ramachandran R, Kakar S. Immunohistochemical approach for the diagnosis of a liver mass on small biopsy specimens. Hum Pathol. 2017;63:1-13.

48. Harding JJ, Nandakumar S, Armenia J, Khalil DN, Albano M, Ly M, et al. Prospective Genotyping of Hepatocellular Carcinoma: Clinical Implications of Next-Generation Sequencing for Matching Patients to Targeted and Immune Therapies. Clin Cancer Res. 2019;25:2116-26.

49. Di Tommaso L, Spadaccini M, Donadon M, Personeni N, Elamin A, Aghemo A, et al. Role of liver biopsy in hepatocellular carcinoma. World J Gastroenterol. 2019;25:6041-52.

50. Di Tommaso L, Destro A, Seok JY, Balladore E, Terracciano L, Sangiovanni A, et al. The application of markers (HSP70 GPC3 and GS) in liver biopsies is useful for detection of hepatocellular carcinoma. J Hepatol. 2009;50:746-54.

51. Sherman M. Histological diagnosis of early hepatocellular carcinoma. Hepatology. 2011;53:1427-9.

\section{(c) BY-NC}

